\title{
Diplonine, a Neurotoxin Isolated from Cultures of the Fungus Stenocarpella maydis (Berk.) Sacc. that Induces Diplodiosis
}

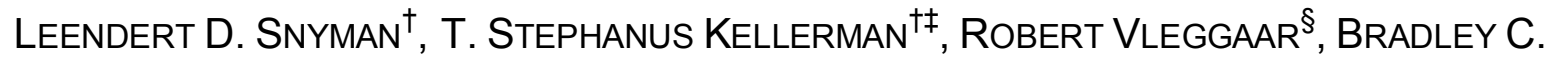
FLETT $^{\#}$, KARIN M. BASSON ${ }^{\dagger \zeta}$, R. ANITRA SCHULTZ ${ }^{\dagger *}$

${ }^{\dagger}$ Section of Toxicology, Agricultural Research Council, Onderstepoort Veterinary Institute, Private Bag X05, Onderstepoort 0110, South Africa

${ }^{\S}$ Department of Chemistry, University of Pretoria, Lynnwood Road, Hillcrest, Pretoria 0002, South Africa

" Crop Protection (Pathology), Agricultural Research Council, Grain Crop Institute, Potchefstroom 2620, South Africa

${ }^{\ddagger}$ Present address: Department of Paraclinical Sciences, Faculty of Veterinary Sciences, Private Bag X04, Onderstepoort 0110, South Africa

${ }^{\zeta}$ Present address: UP Nutrilab, Department of Animal \& Wildlife Sciences, University of Pretoria, Pretoria 0002, South Africa

*Corresponding author (Tel: +27-12-5299261; Fax: +27-12-5299258; E-mail: SchultzA@arc.agric.za) 
ABSTRACT: Diplodiosis is a neuromycotoxicosis of cattle and sheep caused by ingestion of maize infected with the ear-rot fungus Stenocarpella (= Diplodia) maydis. Apart from ataxia, paresis and paralysis, the toxin is responsible for stillbirths and neonatal losses characterized by the presence of spongiform degeneration in the white matter of the brain in the offspring of dams exposed to infected maize cobs. In the present study a toxin, named diplonine, which induced neurological signs in guinea pigs resembling some of those occurring in cattle and sheep, was isolated from S. maydis cultures. Purification of diplonine was achieved by methanol extraction followed by chromatographic separation on silica gel and RP-18 stationary phases. The structure and relative configuration of diplonine was defined by analysis of NMR and MS data as (S)2-amino-2-[(1R,2S)-1-hydroxy-2-methylcyclopropyl]acetic acid or the (S)-2amino-2-[(1S,2R)-diastereomer.

KEYWORDS: $\beta$-cyclopropyl amino acid; diplodiosis; diplonine; maize; neuromycotoxin; Stenocarpella maydis

\section{INTRODUCTION}

Ingestion of maize infected with the common ear-rot fungus Stenocarpella maydis (previously known as Diplodia maydis) causes diplodiosis, a neuromycotoxicosis of ruminants (1). Apart from a suspected outbreak in Australia (2) and recent reports of diplodiosis in Brazil (3) and Argentina (4), diplodiosis is known to occur only in southern Africa, despite the fact that S. maydis is encountered worldwide 
wherever maize is grown (1). The unidentified toxin(s) cause(s) ataxia, paresis and paralysis of cattle and sheep grazing on harvested maize lands in winter when the nutritive value of the sparse natural grazing is poor $(1,5)$. Stillbirths and neonatal losses in the offspring of dams exposed to $S$. maydis in the $2^{\text {nd }}$ and especially the $3^{\text {rd }}$ trimester of pregnancy have also been reported, even in lambs and calves of dams that had never developed signs of diplodiosis (6). Intoxication of the neonates was confirmed histopathologically by the presence of spongiform degeneration in the white matter of the brain (7). Microscopic lesions in adult stock, however, have rarely been observed (1).

Diplodiosis is rated as the $6^{\text {th }}$ most important plant poisoning/mycotoxicosis of sheep and cattle in South Africa (8). It is also one of the most common nervous disorders of livestock in southern Africa and together with facial eczema in New Zealand and lupinosis in Australia is regarded as one of the most frequently diagnosed mycotoxicoses of ruminants $(1,6)$.

Although Mitchell (5) experimentally reproduced diplodiosis in cattle in 1918, the neurotoxin responsible for diplodiosis in stock has yet to be isolated. Isolation of the toxin will enable accurate assessment of the potential risk of grazing infected fields, as not all plant material infected with S. maydis is toxic (9). Infected maize or plant residues could then be monitored in order to advise farmers on prophylactic measures. Furthermore, maize so severely infected with $S$. maydis that it is rendered unmarketable may have severe financial implications for maize producers. However, if harvested fields can be shown to be non-toxic by measuring the toxin content of the residues, this would be a boon for maize farmers. Isolation of the toxin will additionally enable 
characterization of the chemical structure, which would facilitate investigations into the pathogenesis aimed at finding a cure and a preventative treatment for diplodiosis in livestock. The objective of this study, therefore, was to isolate and characterize the neurotoxin responsible for diplodiosis in livestock by using the guinea pig in a bio-assay.

\section{MATERIALS AND METHODS}

Apparatus. Centrifugation was carried out in a centrifuge at $3000 \mathrm{rpm}$ for $30 \mathrm{~min}$ set at $10{ }^{\circ} \mathrm{C}$. Evaporation of the solvents was performed under vacuum at $39{ }^{\circ} \mathrm{C}$ on a rotary evaporator. Optical rotations were measured with a Perkin Elmer 341 polarimeter in a $10.0 \mathrm{~cm}$ cell at the wavelength of the sodium $D$-line $(\lambda=589 \mathrm{~nm})$. Specific rotations are given in units of deg $\mathrm{cm}^{2} / 10 \mathrm{~g}$ and concentrations are given in $\mathrm{g} / 100 \mathrm{~mL}$. Mass spectra were recorded at the University of Stellenbosch, South Africa on a Waters API Q-TOF Ultima spectrometer using the electrospray ionisation (ESI) technique and detection of positive ions with $\mathrm{m} / \mathrm{z}>99$ after calibration with sodium formate. NMR spectra were recorded on a Bruker Avance III 400 spectrometer operating at $400 \mathrm{MHz}$

for ${ }^{1} \mathrm{H}$ and $100 \mathrm{MHz}$ for ${ }^{13} \mathrm{C}$ nuclei using standard Bruker pulse sequences for solutions in $\mathrm{D}_{2} \mathrm{O}$. All chemical shifts are reported as $\delta$ values downfield from $\mathrm{Me}_{4} \mathrm{Si}$.

Chemicals and reagents. All chemicals (Merck, Darmstadt, Germany) used were analytical grade. Column chromatography was performed using silica gel 60 (0.040-0.063 mm, 230-400 mesh ASTM) and RP-18 (LiCroprep, 0.040-0.063 mm) (Merck, Darmstadt, Germany). Thin layer chromatography (TLC) was performed on ALUGRAM SIL G/UV 254 and ALUGRAM RP-18/UV 254 plates (Macherey-Nagel, Düren, 
Germany). Reagents 207 and 250 of the Merck dyeing reagents manual (10) were used as ninhydrin and alkaline potassium permanganate spraying reagents, respectively.

Stenocarpella maydis cultures. Isolation of the neurotoxin was mainly performed with a culture (MRC 2829) used in a previous study to induce diplodiosis in sheep (6). When this culture became depleted, final purification of the neurotoxin was accomplished with culture ARC-GCI 6, one of six cultures obtained from the ARC-GCI.

Inoculum of $S$. maydis was prepared using isolates from infected maize collected in the maize-producing area of South Africa $(6,11)$. Maize cultures were prepared according to the method previously described (11). Jars $(500 \mathrm{~mL}$ ) were filled with maize kernels (400 $\mathrm{mL}$ ) and tap water was added to fill the jars. The maize was allowed to soak for $24 \mathrm{~h}$, the water was decanted and Fries Bosal medium $(30 \mathrm{~mL})$ was added. Jars were autoclaved for 30 min at $120^{\circ} \mathrm{C}$ on 2 consecutive days. Each jar was inoculated with a $1 \mathrm{~cm}^{2}$ block of actively growing mycelium of $S$. maydis cultured on potato-dextrose agar and incubated at $28{ }^{\circ} \mathrm{C}$ for 60 days. Colonized maize was removed from the jars, air-dried for 5 days and milled ( $1 \mathrm{~mm}$ sieve) to a fine meal, which was stored at ca. $5^{\circ} \mathrm{C}$.

Experimental animals. All procedures were carried out in accordance to the South African National Standard (The care and use of animals for scientific purposes [SANS 10386:200X]). Animal experiments were approved by the ARC-OVI Animal Ethics Committee.

Guinea pigs (Dunkin Hartley strain; $\mathrm{n}=14$ ) weighing between 100 and $210 \mathrm{~g}$ were obtained from the Breeding Center at Onderstepoort Biological Products and kept in cages in an environmentally controlled $\left(15-24{ }^{\circ} \mathrm{C} ; 45-70 \%\right.$ relative humidity) animal 
facility at the ARC-OVI Toxicology Biolab. The cages were steam sterilized and provided with vermiculite as bedding (200-300 g per cage). The animals received standard guinea pig/rabbit pellets (Epol Pty. Ltd. SA) and water (with $0.2-1 \mathrm{~g}$ ascorbic acid/L) ad lib.

Animals were deprived of food for ca. $16 \mathrm{~h}$ before being dosed via stomach tube and the nature and degree of clinical signs were recorded and compared to control guinea pigs. Each animal was only used once and euthanized with an overdose (3 $\mathrm{mL} / \mathrm{kg}$ ) of pentobarbitone sodium (200 mg/mL) i.p. after completion of a bioassay.

Bio-assaying for the neurotoxin. The toxicity of the cultures and subsequent column chromatography fractions were evaluated using the guinea pig model (12). The cultures were evaluated by dosing an aliquot of the methanol extract equivalent to $75 \mathrm{~g}$ culture (prepared in ca. $3 \mathrm{~mL}$ water). Fractions collected during column chromatography were combined based on the results of TLC analysis. The combined fractions were evaporated, the residual material dissolved in $3 \mathrm{~mL}$ water and dosed to a guinea pig. Guinea pigs were monitored for the following neurological signs associated with diplodiosis: incoordination, imbalance, paresis, frequent falling, lateral recumbency, paralysis, followed either by recovery or death depending on the severity of the poisoning.

Macro and microscopic examination. The guinea pigs were necropsied and in some cases specimens from various organs were collected and fixed in $10 \%$ buffered formalin and later prepared for microscopic evaluation according to standard operating procedures. Tissue samples were cut and processed overnight in an automated tissue processor for block preparation. After processing, wax blocks were produced, sections 
were cut using a microtome at $5 \mu \mathrm{m}$, mounted on glass slides and stained in an automated Haematoxylin and Eosin stainer before microscopic evaluation.

\section{Purification of the neurotoxin}

Methanol extraction. S. maydis culture $(600 \mathrm{~g})$ was extracted with $1.5 \mathrm{~L}$ methanol on a shaking machine for $24 \mathrm{~h}$, centrifuged, and the supernatant filtered through Whatman No. 1 filter paper. The volume of the filtrate was reduced to $\mathrm{ca} .800$ $\mathrm{mL}$ on a rotary evaporator and de-fatted by extraction three times with equal volumes of hexane where after the methanol extract was evaporated to dryness.

Chromatographic purification. The dried residue $(9.8 \mathrm{~g})$ of the methanol extract was suspended in $50 \mathrm{~mL}$ methanol and fractionated by column chromatography on $200 \mathrm{~g}$ silica gel packed in a $50 \mathrm{~mm}$ diameter glass column using chloroform:methanol:ammonia (25\%) $(40: 60: 8)$ as eluant. The collected fractions were spotted onto two different silica gel coated TLC plates, developed with chloroform:methanol:ammonia (25\%) (40:60:8) and visualized by spraying with either ninhydrin or $50 \%$ sulphuric acid. Two combined fractions were formed by combining fractions on the basis of the TLC analysis viz. 1. Fraction A: Fractions $(8 \times 50 \mathrm{~mL})$ with a $R_{f}$ value $>0.52$ that were visible upon charring with sulphuric acid; and 2 . Fraction B: Fractions $(10 \times 50 \mathrm{ml})$ with a $R_{f}$ value $\leq 0.52$ which showed positive with ninhydrin. Bioassay of the sulphuric acid charring and ninhydrin coloring fractions showed that the neurotoxicity was associated with the ninhydrin coloring fraction (Fraction B), which showed amongst other, prominent spots with $R_{f} 0.52$. This spot was investigated as the possible neurotoxin. 
The procedure was repeated with a second batch of $S$. maydis culture $(600 \mathrm{~g})$ and fractionated in the same way. The toxic Fraction B collected from the two columns were combined and evaporated to dryness. The residue $(4.4 \mathrm{~g})$ was dissolved in $20 \mathrm{~mL}$ methanol and fractionated with the same mobile phase on $100 \mathrm{~g}$ silica gel packed in a $45 \mathrm{~mm}$ diameter column. Fractions $(13 \times 25 \mathrm{~mL})$, showing amongst other the ninhydrincoloring spots with $R_{f} 0.52$ were combined and evaporated to dryness.

The residue $(2.3 \mathrm{~g})$ was dissolved in $10 \mathrm{~mL}$ methanol and fractionated with chloroform:methanol:acetic acid (40:60:0.5) on $60 \mathrm{~g}$ silica gel packed in a $25 \mathrm{~mm}$ diameter column. Fractions $(25 \mathrm{~mL})$ were analyzed by silica gel TLC using chloroform:methanol:ammonia (25\%) (40:60:8) and sprayed with ninhydrin. Fractions $(12 \times 25 \mathrm{ml})$ showing the $R_{f} 0.52$ ninhydrin-positive spot were combined and fractionated under these conditions until proven pure by NMR analysis. The purified substance, however, was characterized by NMR analysis as alanine. The toxicity associated with Fraction $B$, was probably the result of a spill-over from Fraction $A$ by a substance not showing up with ninhydrin. The investigation now turned to Fraction $\mathrm{A}\left(R_{f}>0.52\right)$ of the last column.

Fractions $(7 \times 25 \mathrm{ml})$ constituting Fraction A were spotted onto two RP-18 coated TLC plates, developed with chloroform:methanol:acetic acid (40:60:0.1) and sprayed with either ninhydrin or $50 \%$ sulphuric acid. The first 3 fractions (Fraction A1) $(3 \times 25 \mathrm{ml})$ eluted prior to alanine $\left(R_{f}>0.31\right)$ did not visualize with either ninhydrin or $50 \%$ sulphuric acid and were followed by sulphuric acid charring fractions. The concentrated Fraction A1 was spotted onto two RP-18 coated TLC plates and developed with 
chloroform:methanol:acetic acid (40:60:0.1). The plates, sprayed with either ninhydrin or alkaline potassium permanganate, visualized amongst others, a spot with $R_{f} 0.36$ not seen before. Bio-assay of the combined Fraction A1 elicited neurological signs associated with diplodiosis.

Further purification of this toxic fraction from this point had to be executed with fractions prepared as outlined above from culture ARC-GCI 6 . The dried residue $(0.038$ g) from Fraction A1 was purified by repeated chromatography on $80 \mathrm{~g} \mathrm{RP}-18$ packed in a $25 \mathrm{~mm}$ diameter column. Chromatography was performed by gradient elution with acetonitrile-water (containing $0.1 \%$ acetic acid in each phase) starting with $10 \%$ acetonitrile linearly changed to $90 \%$ acetonitrile. The ratio was changed by 10 percentage units for each $20 \mathrm{~mL}$ eluted. The fractions eluted were spotted onto two RP18 coated TLC plates and developed with chloroform:methanol:acetic acid (40:60:0.1). The plates were either sprayed with ninhydrin or alkaline potassium permanganate. Fractions showing a single substance with $R_{f} 0.36$ that stained with both reagents were pooled $(4 \times 5 \mathrm{~mL})$ and dried $(0.021 \mathrm{~g})$ and the purity verified by NMR spectroscopy. Bioassay of the purified substance elicited clinical signs of neurotoxicity associated with diplodiosis. The remainder of the purified substance was dissolved in $\mathrm{D}_{2} \mathrm{O}$ and freezedried for elucidation of the chemical structure.

Structure elucidation of diplonine. Diplonine was obtained as a dextrorotatory white amorphous solid, with a molecular weight of 145 and molecular formula $\mathrm{C}_{6} \mathrm{H}_{11} \mathrm{NO}_{3}$, established by high-resolution electrospray ionization mass spectrometry. ${ }^{1} \mathrm{H}$ and ${ }^{13} \mathrm{C}$ NMR data are shown in Table 4. 


\section{RESULTS AND DISCUSSION}

Methanol extraction. The clinical signs, post mortem and histopathlogical changes induced in guinea pigs dosed with methanol crude extracts prepared from cultures MRC 2829 and ARC-GCI 1-6 are presented in Table 1. Cultures of ARC-GCI 1-6, among others, were previously tested in guinea pigs in a study to identify a laboratory animal model for diplodiosis (12).

The results showed that guinea pigs dosed with methanol extracts of culture MRC 2829 became mildly to severely poisoned 6 to $36 \mathrm{~h}$ after dosing. Poisoning resulted in clinical signs of neurotoxicity resembling those exhibited during diplodiosis in cattle and sheep. No specific histopathological changes were recorded. All four of the animals recovered 48 to $72 \mathrm{~h}$ after dosing, a feature characteristic of livestock not too severely poisoned by S. maydis. The clinical signs of neurotoxicity induced in guinea pigs by the methanol extracts of culture MRC 2829 were consistent with its effect in causing diplodiosis in sheep (6). Similar results were obtained when methanol extracts of cultures ARC-GCI 3 and 4 were dosed to guinea pigs (Table 1). Methanol extracts of cultures ARC-GCl 1 and 2, however, did not result in any clinical signs. This can be explained by the phenomenon that different isolates of $S$. maydis may differ in toxicity and may even be non-toxic (9). These two cultures served as controls for the others. The results obtained with methanol extracts of cultures ARC-GCI 5 and 6 indicated them to be extremely poisonous as both guinea pigs died after developing clinical signs of neurotoxicity reminiscent of diplodiosis. The high toxicity demonstrated for culture ARC-GCl 6 made it suitable to be used for the isolation of the neurotoxin. 
Doses equivalent to $200 \mathrm{~g}$ culture/kg body weight (BW) and higher had to be administered to guinea pigs (Table 1) in order to induce neurological signs, compared to doses of $10-40 \mathrm{~g} / \mathrm{kg} \mathrm{BW}$ of the material when dosed to the target animals i.e. cattle and sheep (1). There are two possible reasons for the need for these high doses for guinea pigs, either (1) ineffective extraction by methanol, which seems to be partly correct as the toxin isolated appeared to be much more soluble in water than in methanol or (2) that the guinea pig is not as susceptible as the target animals. The latter could be due to one or more of the following reasons: different digestive systems in the guinea pig (mono-gastric) and cattle and sheep (ruminants) and/or different detoxification, metabolism and excretion mechanisms by the liver and kidneys of guinea pigs compared to cattle and sheep and/or a difference in receptor interaction between the central nervous system in guinea pigs and cattle and sheep.

A latent period of $6 \mathrm{~h}$ was observed before clinical signs manifested in guinea pigs that were more severely poisoned (Table 1). In cases where animals were mildly poisoned, they exhibited the first clinical signs only after $12 \mathrm{~h}$. A latent period has also been described with diplodiosis in ruminants (1).

Chromatographic purification. The clinical signs of neurotoxicity exhibited by guinea pigs dosed with the fractions collected after the different processes of chromatographic purification (Table 2) corresponded with those induced by the methanol extract, indicating that the same neurotoxic substance, guided by the guinea pig bio-assay, was followed throughout. The high dose of the purified substance needed to induce neurological signs in the guinea pig is in agreement with the high doses needed to induce neurological signs with methanol extracts of the S. maydis culture. 
The occurrence of clinical signs of neurotoxicity at specific times in the guinea pig dosed with the purified substance is summarized in Table 3 . The occurrence of incoordination, imbalance, paresis in the hind quarters, frequent falling and lateral recumbency, followed by recovery, are typical clinical signs of neurotoxicity that occur in cattle and sheep with diplodiosis (1). The guinea pig in addition showed no gross post mortem lesions and no histologically clear central and peripheral nervous system lesions, which also is in agreement with diplodiosis in cattle and sheep, where lesions in the central nervous system were found to be rare (1). The results suggest that the pure substance, designated diplonine, might be responsible for diplodiosis in ruminants.

It was experienced that most of the toxic principle was lost during chromatographic purification on silica gel. This happened to such an extent that purification of the toxin would be impossible if a small animal model was not available. With the structure of the potential toxin now known, an alternative isolation procedure must be sought that might yield larger quantities of diplonine to be tested for verification in the target animal.

Structure elucidation of diplonine. Diplonine was obtained as a white amorphous solid and had $[\alpha]_{D}+36.0\left(c 1.0, D_{2} \mathrm{O}\right)$. Electrospray ionization mass spectrometry (ESI-MS) established the molecular mass as 145 and the molecular formula as $\mathrm{C}_{6} \mathrm{H}_{11} \mathrm{NO}_{3}$ by accurate mass determination of the $[\mathrm{M}+\mathrm{H}]^{+}(\mathrm{m} / \mathrm{z} 146.0815)$ (calcd for $\mathrm{C}_{6} \mathrm{H}_{12} \mathrm{NO}_{3}:$ 146.0817) and $[\mathrm{M}+\mathrm{Na}]^{+}\left(\mathrm{m} / \mathrm{z}\right.$ 168.0645) (calcd for $\mathrm{C}_{6} \mathrm{H}_{11} \mathrm{NO}_{3} \mathrm{Na}$ : 168.0637) ions.

The NMR data for diplonine are shown in Table 4. The ${ }^{13} \mathrm{C}$ NMR spectrum showed only 6 signals for the carbon atoms and the ${ }^{1} \mathrm{H}$ NMR spectrum multiplet signals 
for only 7 protons. The multiplicities of the different ${ }^{13} \mathrm{C}$ resonances were deduced from the proton-decoupled $\mathrm{CH}, \mathrm{CH}_{2}$ and $\mathrm{CH}_{3}$ subspectra obtained using the DEPT pulse sequence. The signals of the proton-bearing carbon atoms were correlated with specific proton resonances in a two-dimensional (2-D) ${ }^{13} \mathrm{C}\left\{{ }^{1} \mathrm{H}\right\}$ heteronuclear chemical shift correlation experiment (HETCOR) utilizing the one-bond $\left({ }^{13} \mathrm{C},{ }^{1} \mathrm{H}\right)$ spin-spin couplings. The assignments of the signals in the ${ }^{1} \mathrm{H}$ NMR spectrum are based on first-order analysis of the spin systems and chemical shift considerations and were confirmed by a two-dimensional (2D) $\left({ }^{1} \mathrm{H},{ }^{1} \mathrm{H}\right)$ homonuclear chemical shift correlation (COSY) experiment. The two- and three-bond $\left({ }^{13} \mathrm{C},{ }^{1} \mathrm{H}\right)$ connectivity pattern was determined in a HMBC experiment.

The presence of a substituted cyclopropane moiety in the diplonine structure (Figure 1) was evident from the geminal coupling constant of $6.0 \mathrm{~Hz}$ for the $\mathrm{C}(3)$ methylene protons at $\delta_{\mathrm{H}} 0.38$ and 0.81 in the ${ }^{1} \mathrm{H}$ NMR spectrum and the ${ }^{1} \mathrm{~J}_{\mathrm{CH}}$ values of 162 and $165 \mathrm{~Hz}$ in the proton-coupled ${ }^{13} \mathrm{C}$ NMR spectrum for the $\mathrm{C}(3)$ and $\mathrm{C}(2)$ signals at $\delta_{\mathrm{C}} 17.73(\mathrm{t})$ and $17.87(\mathrm{~d})$, respectively. The location of a methyl group at $\mathrm{C}(2)$ of the cyclopropane ring was deduced from the cross-peak observed between the signal for the methyl protons at $\delta_{\mathrm{H}} 1.05(\mathrm{~d})$ and $\mathrm{H}(2)$ at $\delta_{\mathrm{H}} 1.18$ (qdd) in the COSY spectrum and identified a six-proton spin system present in the ${ }^{1} \mathrm{H}$ NMR spectrum of diplonine (1). The methyl group served as the reference point in the structure elucidation of diplonine. The three-bond correlation between the methyl protons at $\delta_{H} 1.05(d)$ and the carbon signal at $\delta_{\mathrm{C}} 58.32(\mathrm{~s})$ in the $\mathrm{HMBC}$ spectrum identified a quaternary carbon at $\mathrm{C}(1)$ of the cyclopropane ring. The identity of one of the $C(1)$ substituents was established by the two- and three-bond correlation between $\mathrm{H}(3 \mathrm{~b})\left(\delta_{\mathrm{H}} 0.81\right)$ and the signals at $\delta_{\mathrm{C}} 58.32(\mathrm{~s})$, 
assigned to $C(1)$, and $\delta_{C} 62.33(d)$ assigned to a methine carbon, $C(4)$ in the HMBC spectrum. The corresponding $\mathrm{C}(4)$ methine proton signal appeared as a singlet at $\delta_{\mathrm{H}}$ $3.22(1 \mathrm{H})$ and showed a two-bond correlation with $\mathrm{C}(1), \delta_{\mathrm{C}} 58.32(\mathrm{~s})$, as well as a carbonyl carbon of a carboxyl group at $\delta_{\mathrm{C}} 172.14(\mathrm{~s})$. The ${ }^{1} \mathrm{~J}_{\mathrm{CH}}$ value of $144 \mathrm{~Hz}$ for the $\delta_{\mathrm{C}}$ $62.33(d)\left[(C(4)]\right.$ signal in the proton-coupled ${ }^{13} \mathrm{C}$ spectrum identified either a hydroxyl or an amino group substituent at $\mathrm{C}(4)$ and thus also at $\mathrm{C}(1)$. The position of the hydroxyl and amino group substituents in diplonine as shown in (1) is based on a comparison of the ${ }^{13} \mathrm{C}$ chemical shift values of 55.61 (s) and $62.91(\mathrm{~d}) \mathrm{ppm}$ for the corresponding carbon atoms in cleonine $(2)(13,14)$, an amino acid constituent of the macrocyclic antibiotic cleomycin (15).

The stereochemistry of the substituted cyclopropane ring in diplonine (1) was determined from the coupling constants in the ${ }^{1} \mathrm{H}$ NMR spectrum and the NOE effects observed in a 2D NOESY experiment (Figure 2). Typically, vicinal coupling between trans protons for the cyclopropyl ring show a coupling of 4.2-5.9 Hz, compared to 8.49.7 $\mathrm{Hz}$ for protons in a cis relationship $(16,17)$. Thus the vicinal coupling of $6.3 \mathrm{~Hz}$ observed for $\mathrm{H}(3 \mathrm{a})$ and $9.8 \mathrm{~Hz}$ for $\mathrm{H}(3 \mathrm{~b})$ with the $\mathrm{C}(2)$ proton placed $\mathrm{H}(3 \mathrm{a})$ in a trans and $\mathrm{H}(3 \mathrm{~b})$ in a cis orientation to $\mathrm{H}(2)$. The subsequent cis relationship between the $\mathrm{C}(2)$ methyl group and $\mathrm{H}(3 \mathrm{a})$ was confirmed by the negative cross-peak in the $2 \mathrm{D}$ NOESY spectrum. The NOEs observed between $\mathrm{H}(3 \mathrm{~b})$ and both $\mathrm{H}(2)$ and $\mathrm{H}(4)$ as well as between $\mathrm{H}(2)$ and $\mathrm{H}(4)$ placed the amino acid group, $\mathrm{H}(2)$ and $\mathrm{H}(4)$ on the same face of the cyclopropane ring. The stereochemistry as shown in (1) or the diastereomeric arrangement (4) is assigned to diplonine on the basis of the NOE results, assuming the $S$ configuration for the amino acid moiety. 
Diplonine was characterized as a substituted $\beta$-cyclopropyl amino acid. Cyclopropyl-substituted amino acids are regularly found in plants and microorganisms and have diverse physiological activities. Formally, most of them are methano-bridged derivatives of proteinogenic amino acids. Among naturally occurring cyclopropanederived amino acids, cyclopropylglycines are the largest family. The group of 1'substituted derivatives consists of the antibacterial compound 2-(1-methylcyclopropyl)glycine (3) (18) and 2-(1-hydroxycyclopropyl)glycine [cleonine (2)] $(14,15)$ and now also diplonine.

According to the literature another toxin, namely diplodiatoxin, has also been isolated from S. maydis $(19,20)$. A study on its mechanism of action indicated inhibition of choline esterase, which was linked to the effect of $S$. maydis poisoning on the central nervous system (21). However, no clinical signs of neurotoxicity related to diplodiosis have yet been demonstrated for diplodiatoxin. Evidence was also put forward that chaetoglobosins, found to be produced by S. maydis (22), comprise the 'unknown toxin' or 'main toxic principle' attributed to S. maydis culture material (22). However, like diplodiatoxin, this has not yet been proven by neurological signs related to diplodiosis.

In this study neurological signs in guinea pigs consistent with those of diplodiosis in ruminant animals have been induced with diplonine. Should diplonine also cause diplodiosis in the target ruminant species, the significance of the current findings will be considerably enhanced. Mycotoxins in staple food of humans and animals are for obvious reasons of considerable medical and veterinary importance. The fact that diplodiosis appears to be more toxic to the foetus than the dam (even ewes that had not shown overt signs of diplodiosis produced stillborn or non-viable lambs) $(6,7)$ is 
particularly disturbing, also from a human point of view, since $S$. maydis is an ubiquitous fungus occurring all over the world wherever maize is grown $(1,23)$. In this connection it must be noted that diplodiosis has been induced in ruminants with pure cultures of $S$. maydis isolated from mouldy maize imported from both North and South America. While acknowledging that the toxin might be heat labile (20) and thus destroyed by cooking, it must be borne in mind that no studies have been conducted on the possible effects of diplodiosis on humans $(1,6,7,23)$.

\section{LITERATURE CITED}

(1) Kellerman, T.S.; Coetzer, J.A.W.; Naudé, T.W.; Botha, C.J. Plant Poisonings and Mycotoxicoses of Livestock in Southern Africa, 2nd Edition, Oxford University Press, Cape Town, South Africa 2005.

(2) Darvall, P.M. Mouldy corn cobs, a danger to cows. Queensland Agric. J. 1964, 90, 692-693.

(3) Riet-Correa, F.; Medeiros R.M.T.; Pfister, J.; Schild A.L.; Dantes, A.F.M. Toxic plants and mycotoxins affecting the nervous system. In Poisoning by plants, mycotoxins and related substances in Brazilian livestock, $1^{\text {st }}$ Edition; Sociedade Vicente Pallotti - Editora, Patos - PB, Brazil 2009; 139-141.

(4) Odriozola, E.; Odeon, A.; Canton, G.; Clemente, G.; Escande, A. Diplodia maydis: a cause of death of cattle in Argentina. New Zealand Vet. J. 2005, 53: 160-161.

(5) Mitchell, D.T. A condition produced in cattle feeding on maize infected with Diplodia zeae. Report on Veterinary Research, Union of South Africa 1918, 7-8, 425-437.

(6) Kellerman, T.S.; Prozesky, L.; Schultz, R.A.; Rabie, C.J.; Van Ark, H.; Maartens, B.P.; Lübben, A. Perinatal mortality in lambs of ewes exposed to cultures of Diplodia maydis (= Stenocarpella maydis) during gestation. Onderstepoort J. Vet. Res. 1991, 58, 297-308. 
(7) Prozesky, L.; Kellerman, T.S.; Swart, P.D.; Maartens, B.P.; Schultz, R.A. Perinatal mortality in lambs exposed to cultures of Diplodia maydis (= Stenocarpella maydis) during gestation. A pathological study of the central nervous system lesion. Onderstepoort J. Vet. Res. 1994, 61, 247-253.

(8) Kellerman, T.S.; Naudé, T.W.; Fourie, N. The distribution diagnoses and estimated economic impact of plant poisonings and mycotoxicoses in South Africa. Onderstepoort J. Vet. Res. 1996, 63, 6590.

(9) Rabie, C.J.; Kellerman, T.S.; Kriek, N.P.J.; Van der Westhuizen, G.C.A.; De Wet, P.J. Toxicity of Diplodia maydis in farm and laboratory animals. Food Chem. Toxicol. 1985, 23, 349-353.

(10) Merck, E. Dyeing reagents for Thin Layer and Paper Chromatography. Darmstadt, Germany 1971.

(11) Flett, B.C.; McLaren, N.W. Optimum disease potential for evaluating resistance to Stenocarpella maydis ear rot in corn hybrids. Plant Dis. 1994, 78, 587-589.

(12) Schultz, R.A.; Snyman, L.D.; Basson, K.M.; Labuschagne, L. The use of a guinea pig model in detecting diplodiosis, a neuromycotoxicosis of ruminants. In Poisoning by Plants, Mycotoxins and Related Toxins, Riet-Correa, F.; Pfister, J.; Schild, A. L.; Wierenga, T., Eds.; CABI, Oxfordshire, UK. 2011. Proceedings of the $8^{\text {th }}$ International Symposium on Poisonous Plants, João Pessoa-Paraiba, Brazil, 4-8 May 2009.

(13) Wessjohann, L.; Krass, N.; Yu, D; de Meijere, A. A new versatile synthesis of ring-substituted 2cyclopropylglycines and related amino acids. Chem. Ber. 1992, 125, 867-882.

(14) Esposito, A.; Piras, P.P.; Ramazzotti, D.; Taddei, M. First stereocontrolled synthesis of (S)cleonine and related cyclopropyl-substituted amino acids. Org. Lett. 2001, 3, 3273-3275.

(15) Kato, K.; Takita, T.; Umezawa, H. Synthesis of cleonine, amino(1-hydroxycycopropylacetic acid, a novel amino acid contained in cleomycin. Tetrahedron Lett. 1980, 21, 4925-4926. 
(16) Avery, T.D.; Greatex, B.W.; Pedersen, D.S.; Taylor, D.K.; Tiekink, E.R.T. A Concise route to $\beta-$ cyclopropyl amino acids utilizing 1,2-dioxines and stabilized phosphonate nucleophiles. J. Org. Chem. 2008, 73, 2633-2640.

(17) Corey, E.J.; Rao, S.A.; Noe, M.C. Catalytic diastereoselective synthesis of cis-1,2-disubstituted cyclopropanols from esters using a vicinal dicarbanion equivalent. J. Am. Chem. Soc. 1994, 116, 93459346.

(18) Shoji, J.; Sakazaki, R.; Kato, T.; Tori, K.; Yoshimura, Y.; Matsuura, S. Isolation of L-2-(1methylcyclopropyl)glycine from Micromonospora miyakonensis sp. nov. II. Isolation and characterization. J. Antibiotics 1981, 34, 370-373.

(19) Louw, W.K.A. Toxic metabolites of Diplodia maydis (Berk.) Sacc. MSc thesis, 1969. University of Pretoria, South Africa.

(20) Steyn, P.S.; Wessels, P.L.; Holzapfel, C.W.; Potgieter, D.J.J.; Louw, W.K.A. The isolation and structure of a toxic metabolite from Diplodia maydis (Berk.) Sacc. Tetrahedron 1972, 28, 4775-4785.

(21) Rahman, M.F.; Rao, S.K.; Achar, P.N. Effect of diplodiatoxin (Stenocarpella maydis) on some enzymatic profiles in male and female rats. Ecotoxicol.Environ. Safety 2002, 52, 267-272.

(22) Wicklow, D.T.; Rogers, K.D.; Dowd, P.F.; Gloer, J.B. Bioactive metabolites from Stenocarpella maydis, a stalk and ear rot pathogen of maize. Fungal Biol. 2011, 115, 133-142

(23) Kellerman, T.S.; Rabie, C.J.; Van der Westhuizen, G.C.; Kriek, N.P.; Prozesky, L. Induction of diplodiosis, a neuromycotoxicosis, in domestic ruminants with cultures of indigenous and exotic isolates of Diplodia maydis. Onderstepoort J. Vet. Res. 1985, 52, 35-42.

\section{Funding Sources}

Financial support by The Maize Trust and the Gauteng Department of Agriculture, Conservation and Environment through the Directorate: Technology Development and Support is gratefully acknowledged. 
Table 1. Clinical signs and post mortem and histopathological changes in guinea pigs dosed with methanol extracts of various cultures

\begin{tabular}{|c|c|c|c|c|c|c|}
\hline \multirow{2}{*}{$\begin{array}{l}\text { Culture } \\
\text { Identity }\end{array}$} & \multirow[t]{2}{*}{$\begin{array}{l}\text { Extract } \\
\text { number }\end{array}$} & \multirow{2}{*}{$\begin{array}{l}\text { Guinea } \\
\text { pig } \\
\text { weight } \\
\text { (g) }\end{array}$} & \multirow{2}{*}{$\begin{array}{c}\text { Dose } \\
\text { Culture } \\
\text { equivalent } \\
\text { (g/kg BW) }\end{array}$} & \multicolumn{2}{|c|}{$\begin{array}{c}\text { Clinical signs observed at specific } \\
\text { time periods }(\mathrm{h})\end{array}$} & \multirow{2}{*}{$\begin{array}{l}\text { Post mortem and } \\
\text { histopathological } \\
\text { changes }\end{array}$} \\
\hline & & & & $6-36$ & $48-72$ & \\
\hline $\begin{array}{l}\text { MRC } \\
2829\end{array}$ & 1 & 187 & 208 & Paresis/Paralysis & Unaffected & Normal \\
\hline $\begin{array}{l}\text { MRC } \\
2829\end{array}$ & 1 & 149 & 259 & Paresis/Paralysis & Unaffected & Normal \\
\hline $\begin{array}{l}\text { MRC } \\
2829\end{array}$ & 2 & 210 & 200 & $\begin{array}{l}\text { Paresis and mild } \\
\text { inco-ordination }\end{array}$ & Unaffected & Normal \\
\hline $\begin{array}{l}\text { MRC } \\
2829\end{array}$ & 2 & 205 & 400 & $\begin{array}{l}\text { Severe inco- } \\
\text { ordination } \\
\text { Frequent falling }\end{array}$ & Unaffected & $\begin{array}{l}\text { Mild oedema of the } \\
\text { brain and minor } \\
\text { non-specific } \\
\text { histopathological } \\
\text { changes }\end{array}$ \\
\hline $\begin{array}{l}\text { ARC- } \\
\text { GCI } 1\end{array}$ & 3 & 156 & 480 & Unaffected & Unaffected & \\
\hline $\begin{array}{l}\text { ARC- } \\
\text { GCl } 2\end{array}$ & 4 & 113 & 663 & Unaffected & Unaffected & \\
\hline $\begin{array}{l}\text { ARC- } \\
\mathrm{GCl} 3\end{array}$ & 5 & 117 & 641 & $\begin{array}{l}\text { Paretic in } \\
\text { hindquarters }\end{array}$ & Unaffected & \\
\hline $\begin{array}{l}\text { ARC- } \\
\text { GCI } 4\end{array}$ & 6 & 136 & 551 & $\begin{array}{l}\text { Frequent falling } \\
\text { Paretic in } \\
\text { hindquarters }\end{array}$ & Unaffected & \\
\hline $\begin{array}{l}\text { ARC- } \\
\text { GCI } 5\end{array}$ & 7 & 113 & 663 & Paretic & Dead & \\
\hline $\begin{array}{l}\text { ARC- } \\
\text { GCl } 6\end{array}$ & 8 & 151 & 496 & $\begin{array}{l}\text { Incoordination } \\
\text { Frequent falling } \\
\text { Lateral recum- } \\
\text { bency } \\
\text { Paralysis }\end{array}$ & Dead & \\
\hline
\end{tabular}


Table 2. Clinical signs exhibited by guinea pigs dosed with toxic fractions collected during different chromatographic purifications on columns

\begin{tabular}{|c|c|c|c|c|}
\hline $\begin{array}{l}\text { Guinea } \\
\text { pig } \\
\text { weight } \\
\text { (g) }\end{array}$ & $\begin{array}{l}\text { Dose } \\
(\mathrm{mg} / \mathrm{kg} \\
\mathrm{BW})\end{array}$ & Fraction bio-assayed & $\begin{array}{l}\text { Clinical signs } \\
\text { induced by the } \\
\text { toxic fraction }\end{array}$ & $\begin{array}{l}\text { Post mortem and } \\
\text { histopathological } \\
\text { changes }\end{array}$ \\
\hline 170 & 3353 & $\begin{array}{l}\text { chloroform:methanol:ammonia } \\
\text { (40:60:8) on } 200 \mathrm{~g} \text { silica gel } \\
\text { Fraction B }\end{array}$ & $\begin{array}{l}\text { Lateral recum- } \\
\text { bency } \\
\text { Paralysis }\end{array}$ & Not investigated \\
\hline 155 & 1483 & $\begin{array}{l}\text { chloroform:methanol:acetic acid } \\
\text { (40:60:0.5) on } 50 \mathrm{~g} \text { silica gel } \\
\text { Fraction A1 }\end{array}$ & $\begin{array}{l}\text { Imbalance } \\
\text { Frequent } \\
\text { falling } \\
\text { Paretic in } \\
\text { hindquarters }\end{array}$ & $\begin{array}{l}\text { No macro or } \\
\text { microscopical lesions } \\
\text { present }\end{array}$ \\
\hline 100 & 1580 & $\begin{array}{l}\text { acetonitrile:water } \\
\text { (gradient elution) on RP-18 } \\
\text { Purified substance }\end{array}$ & $\begin{array}{l}\text { Inco- } \\
\text { ordination } \\
\text { Frequent } \\
\text { falling } \\
\text { Paralysis. }\end{array}$ & $\begin{array}{l}\text { No gross post mortem } \\
\text { lesions and no } \\
\text { histologically clear } \\
\text { central and peripheral } \\
\text { nervous system } \\
\text { lesions }\end{array}$ \\
\hline 105 & $\begin{array}{l}0 \\
\text { (control) }\end{array}$ & & $\begin{array}{l}\text { Normal } \\
\text { behavior }\end{array}$ & Within normal limits \\
\hline
\end{tabular}


Table 3. Occurrence of clinical signs of neurotoxicity at specific times in the guinea pig $(100 \mathrm{~g})$ dosed with $158 \mathrm{mg}$ of the purified substance

\begin{tabular}{c|l}
\hline $\begin{array}{c}\text { Time after dosing } \\
\mathrm{h}\end{array}$ & \multicolumn{1}{|c}{ Clinical signs } \\
\hline 0 & $\begin{array}{l}\text { Normal } \\
\text { Incoordination } \\
\text { Imbalance } \\
\text { Paresis in the hind quarters } \\
\text { Severe degree of paresis in the hind quarters } \\
10\end{array}$ \\
12 & $\begin{array}{l}\text { Frequent falling } \\
\text { In lateral recumbency at times } \\
\text { Lateral recumbency } \\
24\end{array}$ \\
36 & $\begin{array}{l}\text { No clinical signs but still showing righting reflexes } \\
\text { Recovered }\end{array}$ \\
\hline 42 &
\end{tabular}

Table 4. NMR Data for diplonine (1) in $\mathrm{D}_{2} \mathrm{O}$.

\begin{tabular}{|c|c|c|c|c|c|}
\hline atom & $\delta_{\mathrm{c}}$ & & $\delta_{\mathrm{H}}$ & $(\mathrm{HMBC} \mathrm{H} \rightarrow \mathrm{C})$ & NOEs $(\mathrm{H} \rightarrow \mathrm{H})$ \\
\hline 1 & $58.32 \mathrm{~s}$ & & & & \\
\hline 2 & $17.87 \mathrm{~d}\left({ }^{1} J_{C H} 165\right)$ & $1.18 \mathrm{qd}$ & $(J 6.3,6.3,9.8)$ & & $H(3 b), H(4), H(6)$ \\
\hline \multirow[t]{2}{*}{3} & $17.73 \mathrm{t}\left({ }^{1} J_{C H} 162\right)$ & a. $0.38 \mathrm{dd}$ & $(J$ 6.0, 6.3) & $C(1), C(2), C(6)$ & $H(3 b), H(6)$ \\
\hline & & b. $0.81 \mathrm{dd}$ & $(J 6.0,9.8)$ & $C(1), C(2), C(4), C(6)$ & $H(2), H(3 a), H(4)$ \\
\hline 4 & $62.33 \mathrm{~d}\left({ }^{1} J_{C H} 144\right)$ & $3.22 \mathrm{~s}$ & & $C(5), C(1), C(2)$ or $C(3)$ & $H(2), H(3 b)$ \\
\hline 5 & $172.14 \mathrm{~s}$ & & & & \\
\hline 6 & $11.25 \mathrm{q}\left({ }^{1} J_{\mathrm{CH}} 126\right)$ & $1.05 \mathrm{~d}$ & (J 6.3) & $C(3), C(2), C(1)$ & $H(2), H(3 a)$ \\
\hline
\end{tabular}




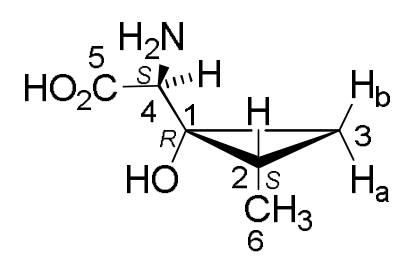

(1)

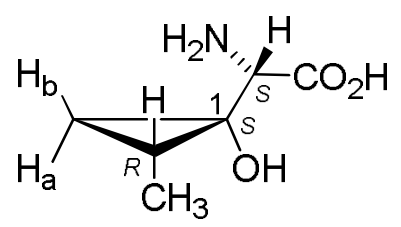

(4)

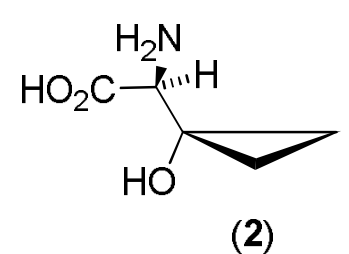

(2)

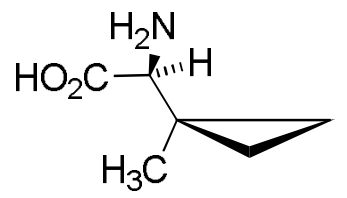

(3)

Figure 1. Chemical structure of diplonine (1) or (4), cleonine (2), and the 1-methyl analogue (3).

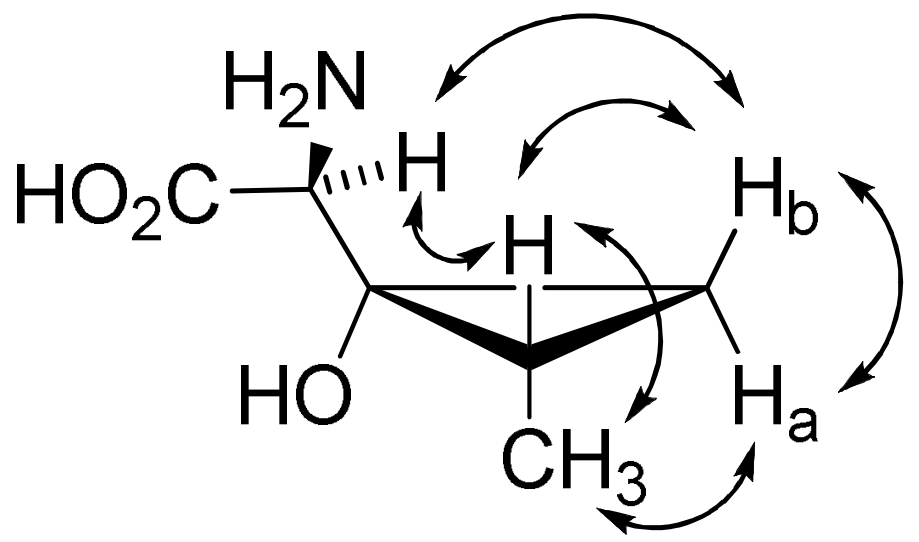

Figure 2. NOE connectivity pattern observed for diplonine (1). 